\title{
The bioreactor overflow device: an undesired selective separator in continuous cultures?
}

\author{
H. J. Noorman, ${ }^{*}$ J. Baksteen, J. J. Heijnen and K. Ch. A. M. Luyben \\ Department of Biochemical Engineering, Delft University of Technology, Julianalaan 67, 2628 BC Delft, The Netherlands
}

(Received 1 March 1991; revised 30 May 1991; accepted 17 June 1991)

\begin{abstract}
Non-homogeneous cell suspensions in a continuous culture may result in a difference between the biomass concentrations in the culture vessel and in the effluent. This will have important consequences for values calculated for stoichiometric and kinetic coefficients. For the bacterium Acinetobacter calcoaceticus it was shown that the cells tend to be buoyant, and because of this, if the vessel overflow device is not designed properly, cells will be selectively removed from the reactor. Two different effluent removal devices were compared, only one of which functioned well. A mathematical model is proposed to explain the observations.
\end{abstract}

\section{Introduction}

The continuous cultivation of micro-organisms is a welldeveloped technique. It is essential that the cells grow in a controlled environment, limited by one or more known substrates. In a steady state, the cellular specific growth and production rates can be fixed according to the requirements of the experimenter. Deliberate disturbance of a steady state may provide information on microbial dynamics in a systematic manner. These features make continuous culture a commonly used research tool (Gottschal, 1990). However, the attractive properties of the method can easily be obstructed by practical problems, often caused by poor equipment or poor experimental precautions. Such problems may, for example, arise because of inappropriate medium composition, wall growth or microbial selection.

It is not always recognized that the effluent composition must be equal to that of the contents of the culture vessel. This implies that the reaction system must be homogeneous (well-mixed). Especially in areas that are more or less stagnant, such as in foam, or in and around the effluent removal device, this will not always be the case.

Continuous plant cell cultures are a well-known example where this homogeneity is not always established. Due to their relatively large volume and high specific density, plant cells tend to sediment in stagnant liquid zones. If the effluent removal device is placed near the gas/liquid surface, cells may be selectively retained in the system (van Gulik et al., 1989). On the other hand, microbial cells may preferentially accumulate at the gas/liquid interface, for example in foam. A simple removal device positioned at the gas/liquid interface will then result in selective removal of the cells (Dählback $e t$ al., 1981). Both situations, sedimentation and flotation, have been observed in cultures of cyanobacteria. This behaviour was caused by differences in the specific density of the cells, which was dependent on the amount of polyglucose stored in the cells, relative to the volume of a gas vacuole (Walsby \& Booker, 1980).

A comparable situation has been observed with the bacterium Acinetobacter calcoaceticus which, when growing in continuous culture in the presence of acetate and xylose, tends to be buoyant. This may have important consequences for measurements of cellular yields, which play a major role in bioenergetic studies. This paper describes the experimental results obtained for this microbial system, using two different effluent removal devices. A simple mathematical model is provided to describe the phenomenon, and to discuss some important biokinetic and bioenergetic implications.

\section{Methods}

\footnotetext{
Organism. Acinetobacter calcoaceticus LMD 79.41 was obtained from the culture collection of the Department of Microbiology and Enzymology, at the Delft University of Technology, The Netherlands. It was maintained on peptone-agar slants and subcultured monthly. At the beginning of each new series of experiments, a new lyophilysed sample was taken from the culture collection.
} 
Growth medium and culture conditions. The cells were grown in continuous culture, in a 2 or 3 litre double-walled bioreactor (Applikon) with a culture volume of about 1 or 2 litres, respectively. The temperature was $30^{\circ} \mathrm{C}$ and the $\mathrm{pH}$ was 8.2 . The $\mathrm{pH}$ was controlled (Applikon E561/3) by addition of $1 \mathrm{M}-\mathrm{KOH}$ or $0.5 \mathrm{M}-\mathrm{H}_{2} \mathrm{SO}_{4}$. The temperature was kept constant by an external thermostat (Lauda MGW). The air flow rate was about $0.030 \mathrm{~m}^{3} \mathrm{~h}^{-1}$ for the 1 litre cultures and $0.060 \mathrm{~m}^{3} \mathrm{~h}^{-1}$ for the 2 litre cultures, and was controlled with a mass flow controller (Brooks $5850 \mathrm{TR}, 0-151 \mathrm{~min}^{-1}$ ). Air was sparged into the reactor and dispersed with two four-bladed turbine stirrers, where the stirrer speed was 1200 r.p.m. The gas flowing out of the reactor was cooled in a condenser $\left(2{ }^{\circ} \mathrm{C}\right)$ and dried (Perma Pure Dryer PD-62512P). The dissolved oxygen concentration never dropped below $25 \%$ of air saturation. The mineral salts medium contained, per litre of demineralized water: $\left(\mathrm{NH}_{4}\right)_{2} \mathrm{SO}_{4}, 4.25 \mathrm{~g} ; \mathrm{MgSO}_{4} .7 \mathrm{H}_{2} \mathrm{O}, 0.10 \mathrm{~g}$; $\mathrm{K}_{2} \mathrm{HPO}_{4}, 0.65 \mathrm{~g} ; \mathrm{KH}_{2} \mathrm{PO}_{4}, 0.50 \mathrm{~g}$; EDTA, $15 \mathrm{mg} ; \mathrm{ZnSO}_{4} .7 \mathrm{H}_{2} \mathrm{O}$, $4.5 \mathrm{mg} ; \mathrm{MnCl}_{2} .4 \mathrm{H}_{2} \mathrm{O}, 1.0 \mathrm{mg} ; \mathrm{CoCl}_{2} .6 \mathrm{H}_{2} \mathrm{O}, 0.3 \mathrm{mg} ; \mathrm{CuSO}_{4} .5 \mathrm{H}_{2} \mathrm{O}$, $0.3 \mathrm{mg} ; \mathrm{Na}_{2} \mathrm{MoO}_{4} .2 \mathrm{H}_{2} \mathrm{O}, 0.4 \mathrm{mg} ; \mathrm{CaCl}_{2} .2 \mathrm{H}_{2} \mathrm{O}, 4.5 \mathrm{mg} ; \mathrm{FeSO}_{4}$. $7 \mathrm{H}_{2} \mathrm{O}, 3.0 \mathrm{mg} ; \mathrm{H}_{3} \mathrm{BO}_{3}, 0.1 \mathrm{mg}$. The xylose/acetate feed ratios and the number of steady states obtained are summarized in Table 1 . The acetate feed concentration was constant at about $60 \mathrm{Cmol} \mathrm{m}^{3}$. The feed medium contained $32 \mathrm{mg} \mathrm{l}^{-1}$ of antifoam, a $30 \%(\mathrm{v} / \mathrm{v})$ silicone emulsion in water $(\mathrm{BDH})$

The experiments have been divided into three series.

1. The culture effluent was pumped out through a single pipe, positioned at the gas/liquid surface, and the culture volume was $I$ litre. Only the optical density of the culture and the effluent were determined.

2. A more advanced device was used, slightly modified from the one used by van Gulik et al. (1989) (see Fig. 1). At regular intervals, the electromagnetic valves were automatically switched on/off to allow the disposal of $1 \%$ of the culture volume. The samples were cooled within $5 \mathrm{~s}$ to $4{ }^{\circ} \mathrm{C}$ with a heat-exchanger, and collected. The culture volume was 2 litres.

3. The effluent was pumped out through a single pipe, positioned at the gas/liquid surface, and the culture volume was 2 litres. The effluent was immediately cooled in an ice-water bath.

Measurement of biomass. Cooled $200 \mathrm{ml}$ samples of culture were centrifuged for $20 \mathrm{~min}$ at 10000 r.p.m. (Sorvall superspeed RC2-B). The pellets were washed three times with ice-water, frozen, and lyophilysed until constant weight.

Measurement of acetate, xylonolactone and xylose. Cooled $5 \mathrm{ml}$ samples of culture were centrifuged, and the acetate content of the supernatant was determined by HPLC (Waters) using an HPX-87H column (eluent 10 meq. $\mathrm{H}_{2} \mathrm{SO}_{4}, 60^{\circ} \mathrm{C}$ ). Detection was spectrophotometric at $214 \mathrm{~nm}$. During the same run the concentration of xylonolactone was determined. The xylose concentration in the supernatant was determined by HPLC (Waters) using an HPX-87P column (eluent water, $85^{\circ} \mathrm{C}$ ). Detection was refractrometric.

Measurement of dissolved oxygen and oxygen in the gas phase. The oxygen concentration in the culture was measured using a galvanic electrode (Biolafitte MG2). The mole fraction of oxygen in the off-gas was analysed paramagnetically (Servomex 1100A model C).

Measurement of $\mathrm{pH}$. $\mathrm{pH}$ was monitored with a standard glass electrode (Ingold 465-35-90-K9).

Consistency check. (A list of symbols etc. is given in an appendix following Results and Discussion.) Prior to the calculations, it was checked whether the degree of reduction balance (a linear combination of the elemental balances) closed. The theoretical 'degree of reduction' recovery can be derived to be:

$$
\left(r_{\mathrm{Ao}}-1 \cdot 065 \cdot r_{\mathrm{Ax}}\right) / r_{\mathrm{As}}=1
$$

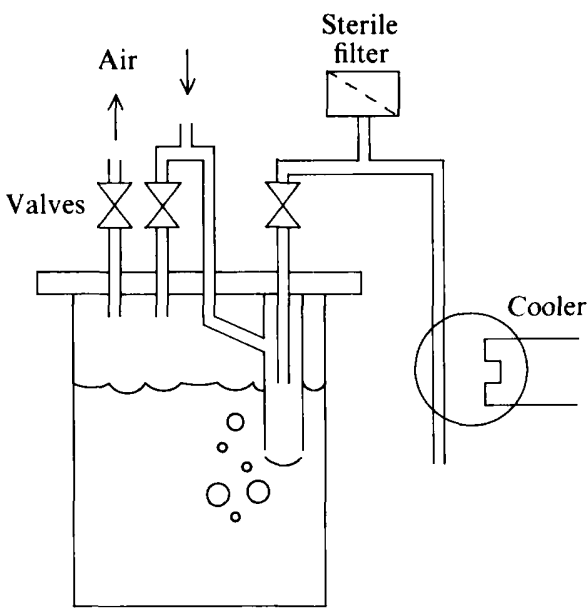

Fig. 1. Diagram of the effluent removal device, slightly modified from van Gulik et al. (1989). The most important components are the three electromagnetic valves and the pipe inside the culture. The detailed functioning is as follows. For most of the time the left hand valve is open and the other two are closed. The liquid level in the culture pipe is kept low continuously by a small air flow, drawn off from the main air stream, and amounting to about $5 \%$ of the total air supply. If the culture volume increases by $1 \%$, the three valves are switched on/off. The liquid level inside the pipe immediately becomes equal to the culture level, the pressure exerted on the culture increases, and the excess liquid is blown out of the system. When about $1 \%$ of the culture has been removed, only gas will flow through the right-hand valve, and the valves are switched to their initial position again.

Table 1. Characteristics of the series of experiments

\begin{tabular}{cccc}
\hline \hline \multirow{2}{*}{$\begin{array}{c}\text { Xylose/acetate } \\
\text { feed ratio }\end{array}$} & Series 1 & Series 2 & Series 3 \\
\cline { 2 - 4 } & 4 & 54 & 5 \\
0 & 0 & 0 & 4 \\
$2 \cdot 5$ & 4 & 32 & 0 \\
$3 \cdot 3$ & 0 & 7 & 0 \\
$6 \cdot 6$ & 0 & \\
\hline
\end{tabular}

As xylose or xylonolactone were not consumed by the cell, the measured concentration of xylonolactone allowed the calculation of the xylose recovery:

$$
-r_{\mathrm{Al}} / r_{\mathrm{Ae}}=1
$$

The experimental data appeared to be consistent with respect to the balances, as the averaged recoveries were 94 and $98 \%$ respectively.

Statistics. The stoichiometric parameters were calculated using multivariate unwejghted linear regression. The independent variables were the specific cell growth rate, $r_{\mathrm{Ax}} / C_{\mathrm{x}}$, and the specific xylose consumption rate, $r_{\mathrm{Ae}} / C_{\mathrm{x}}$. The response variable was the specific acetate consumption rate, $r_{\mathrm{As}} / C_{\mathrm{x}}$. The joint confidence regions of these parameters were evaluated with the matrix and vector equation (Draper \& Smith, 1981):

$$
(\beta-b)^{\mathrm{T}} \cdot X^{\mathrm{T}} \cdot X \cdot(\beta-b) \leq p \cdot s^{2} \cdot F(p, n-p, 1-\alpha)
$$

Here $p$ is the number of parameters $(p=3), n$ is the number of measurements, $n-p$ is the number of degrees of freedom, $1-\alpha$ gives the percentage confidence limits, $F$ is the tabulated value of the $F$ distribution, $s^{2}$ is an estimate of the error variance, $\beta$ is the $p \times 1$ 
parameter vector, $b$ is the $p \times 1$ vector of the best estimates of $\beta$, and $X$ is the $n \times 3$ matrix of independent variables, where one column consists only of ones.

\section{Results and Discussion}

\section{A simple model for selective retainment or removal of cells}

Microbial cells may preferentially be retained in, or withdrawn from the reactor. To simulate this process, a simple mathematical model is proposed here. The model will be applied to growth and product formation by $A$. calcoaceticus LMD 79.41. This aerobic bacterium grows rapidly in the presence of acetate as the sole carbon source. Sinultaneously, D-xylose can be converted to Dxylonolactone, and the bacterium can use the energy released from this incomplete oxidation (van Schie et al., 1987). Consequently, less acetate must be dissimilated to carbon dioxide to satisfy the cellular energy demand, and can therefore be used to build cellular macromolecules. Xylose and xylonolactone cannot be assimilated.

For modelling purposes, it is assumed that the process is being studied in continuous culture with constant volume, and that both substrates are continuously fed to the vessel. The cell suspension is withdrawn from a compartment, with negligibly small volume, in which the biomass concentration can differ from the bulk of the culture. This compartment may, for example, be the inner side of the effluent removal pipe or the gas/liquid interface layer.

\section{Mass balances}

The system is assumed to be composed of eight relevant components: biomass (x), acetate (s), oxygen (o), carbon dioxide, ammonium, xylose (e) and xylonolactone (1). The net conversion rates of these compounds are constrained by balances of the four elements hydrogen, oxygen, carbon and nitrogen. Furthermore, the net conversion rates of xylose and xylonolactone are equal (but opposite). The time dependence of three state variables then suffices for a complete state description. For example, the mass balances for acetate, xylose and biomass read:

$$
\begin{gathered}
\mathrm{d} C_{\mathrm{s}} / \mathrm{d} t=r_{\mathrm{As}}+D \cdot\left(C_{\mathrm{s}, \text { in }}-C_{\mathrm{s}}\right) \\
\mathrm{d} C_{\mathrm{e}} / \mathrm{d} t=r_{\mathrm{Ae}}+D \cdot\left(C_{\mathrm{e}, \text { in }}-C_{\mathrm{e}}\right) \\
\mathrm{d} C_{\mathrm{x}}^{\mathrm{c}} / \mathrm{d} t=r_{\mathrm{Ax}}-D \cdot C_{\mathrm{x}}^{\mathrm{c}} \varepsilon
\end{gathered}
$$

The parameter $\varepsilon$ is the ratio of the biomass concentrations in the small withdrawal compartment, $C_{\mathrm{x}}^{\mathrm{e}}$ and the rest of the culture, $C_{\mathrm{x}}^{\mathrm{c}}$ :

$$
\varepsilon=C_{\mathrm{x}}^{\mathrm{e}} / C_{\mathrm{x}}^{\mathrm{c}}
$$

\begin{tabular}{|c|c|c|c|}
\hline Parameter & Value & Dimension & Reference \\
\hline $\begin{array}{l}\mu_{\max } \\
q_{\mathrm{e}, \max } \\
K_{\mathrm{s}} \\
K_{\mathrm{e}} \\
Y_{\mathrm{sx}} \\
Y_{\mathrm{se}} \\
m_{\mathrm{s}}\end{array}$ & $\begin{array}{c}1.0 \\
4.0 \\
0.1 \\
21 \\
0.43 \\
-19 \\
0.22\end{array}$ & $\begin{array}{l}\mathrm{h}^{-1} \\
\mathrm{Cmol} \mathrm{Cmol}^{-1} \mathrm{~h}^{-1} \\
\mathrm{Cmol} \mathrm{m}^{-3} \\
\mathrm{Cmol} \mathrm{m}^{-3} \\
\mathrm{Cmol} \mathrm{Cmol} \\
\mathrm{Cmol} \mathrm{Cmol} \\
\mathrm{Cmol} \mathrm{Cmol}^{-1} \mathrm{~h}^{-1}\end{array}$ & $\begin{array}{l}\text { H. J. Noorman, unpublished } \\
\text { Dokter et al. (1987) } \\
\text { See Results }\end{array}$ \\
\hline
\end{tabular}

Table 2. Model parameter values for the A. calcoaceticus system

$\varepsilon$ is greater than 1 if the cells float, and lower than 1 if the cells sediment.

\section{Kinetics and stoichiometry}

The kinetic expressions for the net conversion rates are kept as simple as possible. For cell growth, the Monod equation is assumed to be valid:

$$
r_{\mathrm{Ax}}=\mu_{\max } C_{\mathrm{s}} /\left(C_{\mathrm{s}}+K_{\mathrm{s}}\right) \cdot C_{\mathrm{x}}^{\mathrm{c}}
$$

Xylose is converted by a single enzyme, which is located in the periplasmic space (Matsushita et al., 1989). The specific conversion rate is described by a MichaelisMenten type equation:

$$
-r_{\mathrm{Ae}}=q_{\mathrm{e}, \max } \cdot C_{\mathrm{e}} /\left(C_{\mathrm{e}}+K_{\mathrm{e}}\right) C_{\mathrm{x}}^{\mathrm{c}}
$$

The rate of acetate consumption is related to the two other rates by a Pirt-type equation:

$$
-r_{\mathrm{As}}=r_{\mathrm{Ax}} \cdot\left(1 / Y_{\mathrm{sx}}\right)-r_{\mathrm{Ae}} \cdot\left(1 / Y_{\mathrm{se}}\right)+m_{\mathrm{s}} \cdot C_{\mathrm{x}}^{\mathrm{c}}
$$

The most likely values of the model parameters for the A. calcoaceticus system are given in Table 2.

\section{Simulation}

During the simulations, cells growing with and without xylose are considered. Because the system was studied in the steady state only, the time differentials in equations (4)-(6) become zero. It is assumed that the biomass concentration can be determined in two different ways: from samples drawn directly from the culture, or from the effluent stream. If $\varepsilon$ is not equal to 1, the biomass concentrations obtained will differ proportionally with $\varepsilon$.

Fig. 2 shows the effect of some $\varepsilon$-values on $C_{x}^{c}$ as a function of the dilution rate, the xylose/acetate ratio being $3.3 C \mathrm{~mol} \mathrm{Cmol}^{-1}(\mathrm{Cmol}$ is the amount containing $1 \mathrm{~mol}$ of the element carbon). Fig. 3 shows the prediction of $C_{\mathrm{x}}^{\mathrm{e}}$ under the same conditions. It is clear that $C_{\mathrm{x}}^{\mathrm{c}}$ is much more sensitive to variations in $\varepsilon$ than $C_{\mathrm{x}}^{\mathrm{e}}$. This can be explained as follows. 


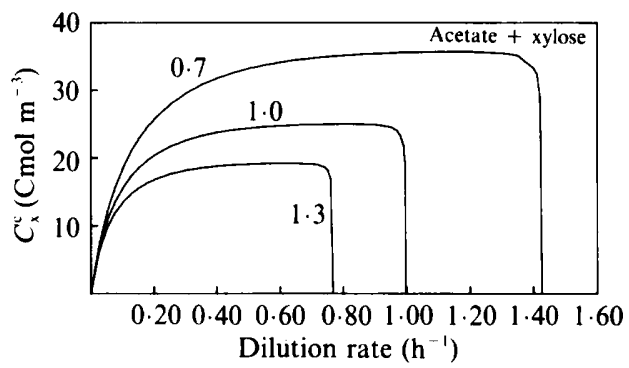

Fig. 2

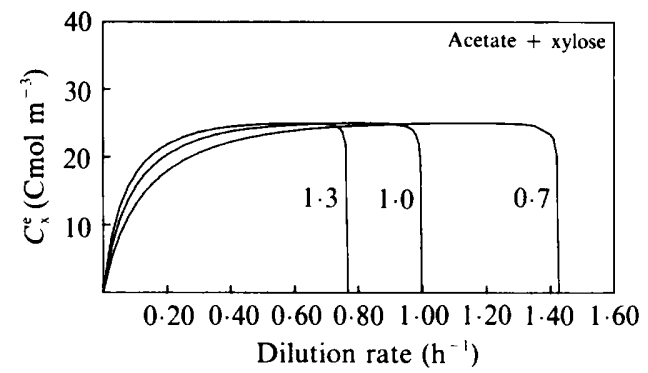

Fig. 3

Fig. 2. Simulation of the effect of different $\varepsilon$-values on the biomass concentration, obtained from reactor samples, as a function of the dilution rate. Parameters as in Table 2. Xylose/acetate feed ratio $3.3 \mathrm{Cmol} \mathrm{Cmol}^{-1}$.

Fig. 3. Simulation of the effect of different $\varepsilon$-values on the biomass concentration, obtained from effluent samples, as a function of the dilution rate. Parameters as in Table 2. Xylose/acetate feed ratio $3 \cdot 3 \mathrm{Cmol} \mathrm{Cmol}^{-1}$.

From equation (6) it follows that the specific growth rate varies with $\varepsilon$. If $\varepsilon$ is greater than 1 , the specific growth rate of the culture is greater than the dilution rate. $C_{\mathrm{x}}^{\mathrm{e}}$ then increases because less substrate is used for maintenance purposes, and more for growth. This increase of $C_{\mathrm{x}}^{\mathrm{e}}$, caused by a decreasing maintenance load, is relatively small, and the effect fades away at high dilution rates. $C_{\mathrm{x}}^{\mathrm{c}}$, on the other hand, falls proportionally with $\varepsilon$, which is quite substantial for $\varepsilon$-values widely deviating from 1.

Another conclusion that can be drawn is that the dilution rate at which cell washout occurs is inversely proportional to $\varepsilon$. Consequently, the apparent maximum specific growth rate, $\mu_{\max }$, alters with changing $\varepsilon$-values.

\section{Evaluation of model parameters}

The determination of the stoichiometric parameters, $Y_{\mathrm{sx}}$, $Y_{\mathrm{se}}$, and the kinetic parameters, $\mu_{\max }, q_{\mathrm{e}, \max }, K_{\mathrm{s}}, K_{\mathrm{e}}$ and $m_{\mathrm{s}}$, depends on the way the biomass concentration is measured: either from culture samples or from the effluent. If the samples are taken from the effluent, the biomass production rate, $r_{\mathrm{Ax}}$, equals $D \cdot C_{\mathrm{x}}^{\mathrm{e}}$. Using equations (7) and (10) it then follows:

$$
-r_{\mathrm{As}} / C_{\mathrm{x}}^{\mathrm{e}}=D \cdot\left(1 / Y_{\mathrm{sx}}\right)-r_{\mathrm{Ae}} / C_{\mathrm{x}}^{\mathrm{e}} \cdot\left(1 / Y_{\mathrm{se}}\right)+m_{\mathrm{s}} / \varepsilon
$$

It is clear that for this situation the apparent maintenance coefficient depends on $\varepsilon$.

If the sample is taken directly from the culture, the biomass production rate, $r_{\mathrm{Ax}}$, is equal to $D \cdot C_{\mathrm{x}}^{\mathrm{c}} \cdot \varepsilon$. Combining this result with equations (7) and (10) gives:

$$
-r_{\mathrm{As}} / C_{\mathrm{x}}^{\mathrm{c}}=D \cdot\left(\varepsilon / Y_{\mathrm{sx}}\right)-r_{\mathrm{Ae}} / C_{\mathrm{x}}^{\mathrm{c}} \cdot\left(1 / Y_{\mathrm{se}}\right)+m_{\mathrm{s}}
$$

In this case, the calculated value of the yield coefficient $Y_{\mathrm{sx}}$ depends on $\varepsilon$, whereas $Y_{\mathrm{se}}$ and $m_{\mathrm{s}}$ do not.

For the kinetic equations, the same reasoning applies. The Monod equation (8), can be reworked into:

$$
1 / D=\varepsilon / \mu_{\max }+K_{\mathrm{s}} \cdot \varepsilon / \mu_{\max } \cdot\left(1 / C_{\mathrm{s}}\right)
$$

Irrespective of the way the biomass concentration is obtained, the apparent $\mu_{\max }$ differs from the true value by a factor $\varepsilon . K_{\mathrm{s}}$, on the other hand, is not affected by $\varepsilon$.

Monitoring $C_{\mathrm{x}}^{\mathrm{c}}$, the true values of $q_{\mathrm{e}, \max }$ and $K_{\mathrm{e}}$ can be easily obtained from equation (9). However, measuring $C_{\mathrm{x}}^{\mathrm{e}}$, gives:

$$
-C_{\mathrm{x}}^{\mathrm{e}} / r_{\mathrm{Ae}}=\varepsilon / q_{\mathrm{e}, \max }+K_{\mathrm{e}} \cdot \varepsilon / q_{\mathrm{e}, \max } \cdot\left(1 / C_{\mathrm{e}}\right)
$$

If selective removal or retention of cells is not taken into account, the value of $q_{\mathrm{e}, \max }$ is estimated incorrectly, but $K_{\mathrm{e}}$ is not.

\section{Proving the occurrence of selective cell removal (series 1)}

Eight steady states were obtained using a conventional effluent pipe, touching the gas/liquid interface. The optical density of the culture and the effluent were measured at $660 \mathrm{~nm}$. Samples were taken from the culture according to the standard method via a separate pipe, immediately after the effluent stream had been sampled. The dilution rate and the xylose feed concentration were varied, and the effluent pipe was mounted in two different positions: one where air bubbles were floating, and another where this was not the case. The results are given in Table 3 . Because only the optical density was measured, and not the true biomass concentration, the Cmol-based stoichiometric coeffcients could not be determined. The residence time of the culture in the effluent pipe did not affect the $\mathrm{OD}_{660}$. Even $30 \mathrm{~min}$ after sampling, the optical density was unchanged.

The results indicate that pumping-off the cell suspension at a place where air bubbles are present can cause $\varepsilon$-values above 1 . In the cultures where xylose was added, the average value of $\varepsilon$ was $1 \cdot 14$. For cultures in the absence of xylose, $\varepsilon=1.07$. However, pumping-off the liquid from a position without air bubbles resulted in an $\varepsilon$-value of $1 \cdot 01$, irrespective of the presence of xylose. 
Table 3. Optical density of the culture and the effluent, as a function of dilution rate, xylose/acetate feed ratio, and positioning of the effluent removal pipe (series 1)

The standard deviation of $\varepsilon$ was about 0.01 .

\begin{tabular}{|c|c|c|c|c|c|}
\hline \multirow{2}{*}{$\begin{array}{c}\text { Dilution } \\
\text { rate } \\
\left(\mathrm{h}^{-1}\right)\end{array}$} & \multirow{2}{*}{ 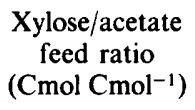 } & \multicolumn{2}{|c|}{$O D_{660}$} & \multirow[b]{2}{*}{$\varepsilon$} & \multirow{2}{*}{$\begin{array}{c}\text { Air } \\
\text { bubbles }\end{array}$} \\
\hline & & Culture & Effluent & & \\
\hline $0 \cdot 15$ & 0 & 1.09 & $1 \cdot 16$ & 1.06 & Yes \\
\hline 0.35 & 0 & 1.40 & 1.52 & 1.08 & Yes \\
\hline $0 \cdot 20$ & 0 & $1 \cdot 18$ & 1.20 & 1.02 & No \\
\hline 0.40 & 0 & $1 \cdot 30$ & 1.27 & 1.98 & No \\
\hline $0 \cdot 18$ & $3 \cdot 3$ & 1.24 & 1.26 & 1.02 & No \\
\hline 0.42 & $3 \cdot 3$ & 1.48 & 1.50 & 1.01 & No \\
\hline $0 \cdot 20$ & $3 \cdot 3$ & $1 \cdot 26$ & 1.40 & $1 \cdot 11$ & Yes \\
\hline 0.40 & $3 \cdot 3$ & $1 \cdot 13$ & 1.31 & $1 \cdot 16$ & Yes \\
\hline
\end{tabular}

Thus, under the conditions tested, the cells are likely to be buoyant, and the simple effluent removal device is not suitable under all circumstances.

\section{Calculating the most likely stoichiometric coefficients (series 2)}

In the second series of experiments, the surplus medium was periodically removed via a device controlled by an electromagnetic valve system. The culture volume was kept constant within $1 \%$. A large number of steady states was obtained, at a broad range of dilution rates, and in both the absence and presence of xylose. Using this system, only $\varepsilon$-values equal to 1.00 (standard deviation 0.01 ) were measured. Thus, this device proved to be functioning properly. The most likely values of the stoichiometric parameters were determined (Table 4).

It is clear that the xylose conversion significantly increases the cell yield: $-1 / Y_{\text {se }}$ is greater than 0 . Furthermore, the cell yield coefficient is about $0.43 \mathrm{Cmol} \mathrm{Cmol}^{-1}$, and the maintenance coefficient is $0.22 \mathrm{Cmol} \mathrm{Cmol}^{-1} \mathrm{~h}^{-1}$.

It is important to note that the overflow device does not hamper the accurate determination of the gas exchange rates. Although during the short periods of overflow the culture pressure is increased, the measured oxygen consumption rates remain consistent with the conservation of elements (as described in Methods).

\section{An example where false conclusions may be drawn (series 3)}

In an early stage of the project, when the nonhomogeneity had not yet been recognized, nine steady states for the same system were obtained. These can now be re-evaluated. During these experiments, a single pipe
Table 4. Most likely stoichiometric parameters for the A. calcoaceticus system, using the advanced effluent removal device (series 2)

The number of observations, $n=93$; as an estimate of the error variance, $s^{2}=0.028$.

\begin{tabular}{cccc}
\hline \hline Parameter & Value & $95 \%$ Confidence region & \multicolumn{1}{c}{ Dimension } \\
\hline$m_{\mathrm{s}}$ & 0.22 & $0 \cdot 16-0.29$ & $\mathrm{Cmol} \mathrm{Cmol} \mathrm{h}$ \\
$Y_{\mathrm{sx}}$ & 0.43 & $0 \cdot 40-0.45$ & $\mathrm{Cmol} \mathrm{Cmol}$ \\
$Y_{\mathrm{se}}$ & -19 & $-9--29$ & $\mathrm{Cmol} \mathrm{Cmol}{ }^{-1}$ \\
\hline \hline
\end{tabular}

Table 5. Stoichiometric parameters for the A. calcoaceticus system, using the simple effluent removal pipe (series 3)

Measurements of biomass concentration were done in the effluent. The number of observations, $n=9$; as an estimate of the error variance, $s^{2}=0.0017$.

\begin{tabular}{cccc}
\hline \hline Parameter & Value & $95 \%$ Confidence region & Dimension \\
\hline$m_{\mathrm{s}}$ & 0.17 & $0 \cdot 10-0.24$ & $\mathrm{Cmol} \mathrm{Cmol} \mathrm{h}^{-1}$ \\
$Y_{\mathrm{sx}}$ & 0.40 & $0.36-0.46$ & $\mathrm{Cmol} \mathrm{Cmol}$ \\
$Y_{\mathrm{se}}$ & -6.9 & $-5.3--9.8$ & $\mathrm{Cmol} \mathrm{Cmol}$ \\
\hline \hline
\end{tabular}

was used to remove the effluent, and selective biomass removal could well have occurred. A small layer of foam was generally present above the gas/liquid surface. The biomass concentration was measured only in the effluent. The results can be analysed in the same way as before, and are summarized in Table 5 (assuming $\varepsilon=1$ ).

Comparing the results with those of series 2 , the $95 \%$ joint confidence regions of both parameter sets appear to be separate (Fig. 4). This implies that the parameter vectors are statistically different. The question is, then, which parameters are responsible for this. The apparent maintenance coefficient is statistically equivalent to the result obtained from series 2 . Also, the apparent yield coefficient, $Y_{\mathrm{sx}}$, cannot be distinguished from the most likely value. However, the yield increase in the presence of xylose is much higher (due to a lower absolute value of $Y_{\text {se). }}$.

The next question is whether this difference can be explained by the model, taking $\varepsilon$ to be constant under all conditions. From equation (11) it follows that, if the effluent is sampled while $\varepsilon$ is not equal to 1 , only the apparent maintenance coefficient is dependent on the value of $\varepsilon$. However, we have found that only the yield coefficient, $Y_{\mathrm{se}}$, takes another value. This means that the difference in $1 / Y_{\text {se }}$ cannot be explained if $\varepsilon$ is treated as equal in both systems with and without xylose added.

Alternatively, $\varepsilon$ may differ with the experimental conditions. For example, as was found for series $1, \varepsilon$ is 




Fig. 4. Three-dimensional representation of the joint confidence regions of the maintenance and yield parameters obtained from experiment series 2 (most likely values, small ellipsoid) and series 3 (apparent values, large ellipsoid). The joint regions are separate, indicating that the parameter sets can be statistically distinguished. The middle rings of the two ellipsoids cross the horizontal plane.

dependent on the dilution rate or the xylonolactone concentration.

Extrapolating the results obtained from series $1, \varepsilon$ may be dependent on the dilution rate, according to

$$
\varepsilon=0 \cdot 25 \cdot D+1.06
$$

in the presence of xylose, and

$$
\varepsilon=0 \cdot 10 \cdot D+1.05
$$

for cultures growing on acetate alone. However, linear regression of $\varepsilon \cdot r_{\mathrm{Ae}} / C_{\mathrm{x}}$ against $\varepsilon \cdot r_{\mathrm{Ae}} / C_{\mathrm{x}}$ and $\varepsilon \cdot D$ did not result in significant parameter differences, and the proposed equations (15) and (16) do not seem to be valid here.

After some calculations it was found that the apparent parameters are in agreement with the most likely values (Table 4), by taking the value of $\varepsilon$ for the cultures with xylose to be about 2.4 times higher $(95 \%$ confidence interval 1.3-5) than for those in which acetate only was present. The yield coefficient $Y_{\mathrm{sx}}$ is estimated to be 0.44 (95\% confidence region $0.39-0.49$ ), which still agrees with the most likely value. It should be noted, however, that the factor $2 \cdot 4$ may be unrealistically high.

\section{Additional results}

After the above problem was noticed, the functioning of the effluent removal devices of a number of other continuous microbial cultures was checked. It appeared that there were several other cultures in which effluent removal did not function properly. Two examples are given here.

1. With aerobic cultures with the sulphur-oxidizing bacterium Thiobacillus acidophilus, using a single pipe positioned at the gas/liquid interface, it was found that $\varepsilon=1.06$ (standard deviation 0.01 ). The problem could be solved by mounting a wider second pipe around the first pipe, with the opening below the liquid level (J. T. Pronk, unpublished results).

2. Anaerobic cultures with Saccharomyces cerevisiae CBS 8066, growing in the presence of glucose and maltose, easily form agglomerates. Several commercial devices (Applikon) with double pipes for effluent removal were tried, but all gave $\varepsilon$ values below 1 , in the range $0 \cdot 70-0.94$. The problem could be solved by periodic disposal of the culture surplus, using a simple liquid level sensor ( $R$. Weusthuis, unpublished results).

\section{Final remarks}

The correct functioning of a continuous culture may be obstructed by an inefficient effluent removal device. The appearance and magnitude of this phenomenon greatly depend on the microbial system in use, and the specific experimental conditions. With a simple mathematical model it can be shown that stoichiometric and kinetic coefficients can easily be given the wrong value, which is proportional to the value of $\varepsilon$. Conclusions concerning microbial energetics and kinetics, often based on relatively small parameter differences, likewise, will then also be incorrect. Apparent parameter values become dependent on the efficiency of cell retainment or removal, and whether samples are taken from the culture or the effluent stream.

This problem arose during the study of the energetics of the bacterium $\boldsymbol{A}$. calcoaceticus. It became clear that these cells may tend to reside preferentially at the gas/liquid interface. However, this effect is not equally strong under all conditions, and quantification with the available data is difficult. If xylose is added to the system, the buoyant properties of the bacterium may be more pronounced, compared with cells grown in its absence.

The position and type of the reactor effluent removal device were shown to be important in choosing a correct fermenter set-up. Using a design in which the effluent is periodically removed by electromagnetic valves, the reactor effluent composition was always the same as the reactor contents. This device was originally developed for cultures with sedimenting cells, but proved to also be useful for buoyant cells. Furthermore, it proved to be very robust, as it worked almost continuously for a period of 2 years without malfunctioning. However, this is by no means the only possible solution, because for a number of other systems a more simple device also appeared to be appropriate.

We thank Dr L. A. Robertson for critical reading of the manuscript. 


\section{Appendix: Nomenclature}

\section{Symbols}

$b \quad$ Vector of most likely parameters $(3 \times 1)$

$C_{\mathrm{i}} \quad$ Concentration in reactor

$C_{\mathrm{i}} \quad$ Concentration in reactor

$D \quad$ Dilution rate

$K_{\mathrm{i}} \quad$ Monod or Michaelis-

Menten saturation

constant

$m_{\mathrm{s}} \quad$ Maintenance coefficient

$n \quad$ No. of measurements

$p \quad$ No. of parameters $(p=3)$

$q_{\text {e.max }}$ Maximal specific xylose conversion rate

$r_{\mathrm{Ai}} \quad$ Net conversion rate

$s^{2} \quad$ Estimate of the error variance

$t \quad$ Time

$X \quad$ Matrix of independent variables $(n \times 3)$

$Y_{\mathrm{ij}} \quad$ Yield coefficient

Greek

$\beta \quad$ Parameter vector $(3 \times 1)$

$\varepsilon \quad$ Ratio of biomass

concentrations

$\mu_{\max } \quad$ Maximal specific growth rate

\section{Subscripts}

$\begin{array}{ll}\text { e } & \text { Xylose } \\ 1 & \text { Xylonolactone }\end{array}$

$\mathrm{Cmol} \mathrm{m}^{-3}$

$\mathrm{Cmol} \mathrm{m}^{-3}$

$\mathrm{h}^{-1}$

$\mathrm{Cmol} \mathrm{m}{ }^{-3}$

$\mathrm{Cmol} \mathrm{Cmol}^{-1} \mathrm{~h}^{-1}$

$\mathrm{Cmol} \mathrm{Cmol}^{-1} \mathrm{~h}^{-1}$

$\mathrm{Cmol} \mathrm{m} \mathrm{m}^{-3} \mathrm{~h}^{-1}$

h

$\mathrm{Cmol} \mathrm{Cmol}{ }^{-1}$

$\begin{array}{ll}\text { o } & \text { Oxygen } \\ \text { s } & \text { Acetate } \\ \text { x } & \text { Biomass }\end{array}$

Superscripts

c Culture

e Effluent

\section{References}

DäHlback, B., Hermannsson, M., KJelleberg, S. \& Norkarans, B. (1981). The hydrophobicity of bacteria - an important factor in their initial adhesion at the air-water interface. Archives of Microbiology 128, 267-270.

Dokter, P., Pronk, J. T., van Schie, B. J., van Dijken, J. P. \& Duine, J. A. (1987). The in vivo and in vitro substrate specificity of quinoprotein glucose dehydrogenase of Acinetobacter calcoaceticus LMD 79.41. FEMS Microbiology Letters 43, 195-200.

Draper, N. R. \& SMIth, H. (1981). Applied Regression Analysis, 2nd edn, p. 109. New York: Wiley \& Sons.

GotTschal, J. C. (1990). Different types of continuous culture in ecological studies. Methods in Microbiology 22, 87-124.

van Gulik, W. M., Meijer, J. J., Ten Hoopen, H. J. G., Luyben, K. CH. A. M. \& Libbenga, K. R. (1989). Growth of a Catharanthus roseus cell suspension culture in a modified chemostat under glucose limiting conditions. Applied Microbiology and Biotechnology 30, 270275.

Matsushita, K., Shinagawa, E., Adachi, O. \& Ameyama, M. (1989). Quinoprotein D-glucose dehydrogenase of the Acinetobacter calcoaceticus respiratory chain: membrane-bound and soluble forms are different molecular species. Biochemistry 28, 6276-6280.

vaN SChIE, B. J., RouWenhorst, R. J., DE BoNT, J. A. M., VAN DIJKen, J. P. \& KuENEN, J. G. (1987). An in vivo analysis of the energetics of aldose oxidation by Acinetobacter calcoaceticus. Applied Microbiology and Biotechnology 26, 560-567.

W ALSBY, A. E. \& BOOKER, M. J. (1980). Changes in buoyancy of a planktonic blue-green algae in response to light intensity. British Phycological Journal 15, 311-319. 